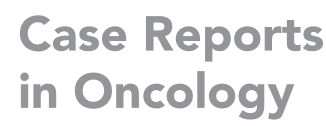

Case Reports

in Oncology

\title{
Primary Gastric Lymphoma Invading Spleen, Pancreas, and Transverse Colon
}

\author{
Petr Lochman ${ }^{a}$ b jiří Párala, b \\ aDepartment of Field Surgery, Faculty of Military Health Sciences, University of Defence, \\ Hradec Králové, Czech Republic; 'bepartment of Surgery, Charles University Faculty of \\ Medicine and University Hospital, Hradec Králové, Czech Republic
}

\section{Keywords}

Primary gastric lymphoma · Penetration · Proximal gastrectomy · Splenectomy · Distal pancreatectomy · Left colectomy

\section{Abstract}

Primary gastric lymphoma is a relatively rare tumour which is not primarily indicated on for surgical treatment. We present a case of locally advanced primary gastric lymphoma with penetration to the surrounding organs that had to be managed surgically. The proximal gastrectomy with splenectomy, distal pancreatectomy, and left colectomy was performed. We reached $\mathrm{R} 0$ resection, and patient was recovered well.

\section{Introduction}

Primary gastric lymphoma involves only $5 \%$ of all gastric malignancies, but it is the commonest extranodal lymphoma at all [1]. Chemotherapy, radiotherapy, surgery, or their combination play role in the treatment, however optimal method, especially in early stages, still remains controversial [2,3].

\section{Case Report}

We report a case of 55-year-old, otherwise healthy, man who had been examined for 2 months lasting abdominal pain in the left flank, weight loss, and melena. The contrast abdominal X-ray proved a leak of water-soluble iodine contrast stuff from stomach to the left hypochondrium and gastroscopy had shown ulcer lesion of proximal third of stomach which penetrated to the spleen (Fig. 1, 2). Multiple biopsies taken revealed diffuse large B-cell

\section{Karger"}




\section{Case Reports in Oncology}

Case Rep Oncol 2021;14:928-930

DOI: $10.1159 / 000516759$

(c) 2021 The Author $(s)$
www.karger.com/cro

Lochman and Páral: Primary Gastric Lymphoma

Fig. 1. Contrast abdominal X-ray - a massive leak of perorally administered iodine contrast stuff into the peritoneal cavity.

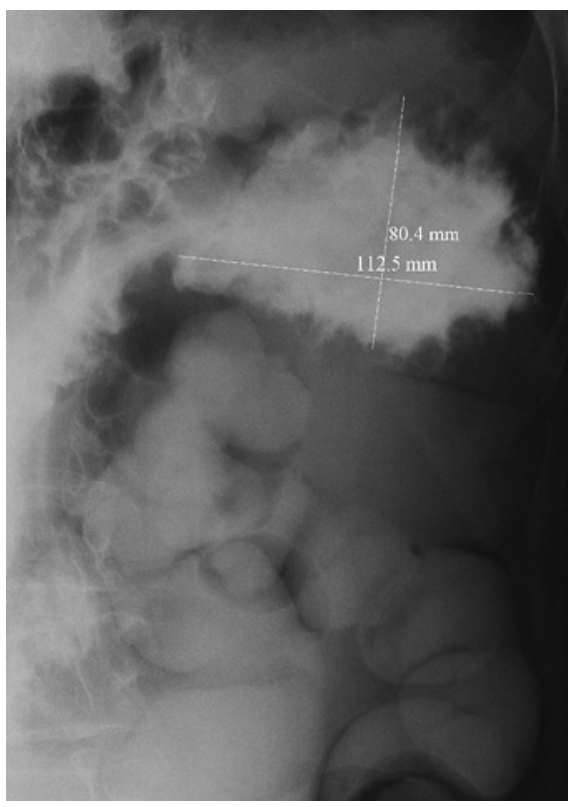

Fig. 2. Gastroscopy - ulcer penetrating to the spleen.

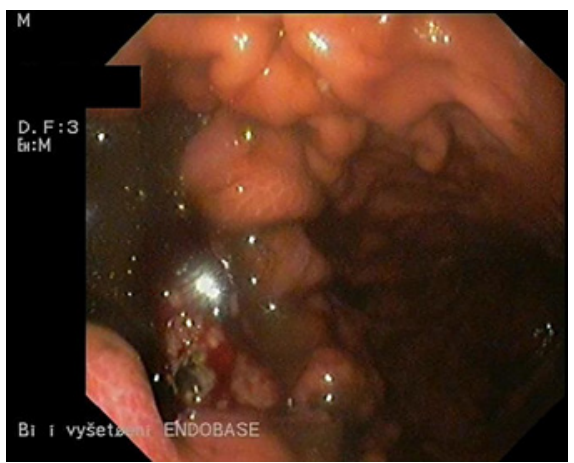

Fig. 3. CT scan - penetration of gastric ulcer to the spleen and infiltration of transverse colon.

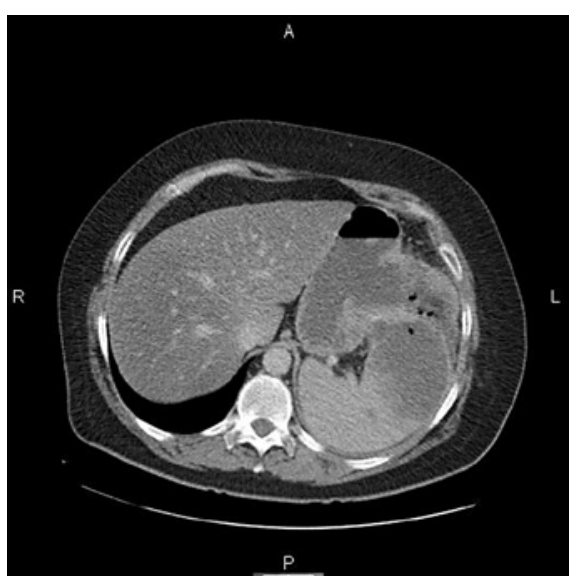

lymphoma that invaded the spleen, pancreas, and transverse colon according to the abdominal CT scan (Fig. 3). Patient underwent proximal gastrectomy with splenectomy, left side pancreatectomy and extended left colectomy. The postoperative course was complicated with subphrenic abscess formation on the left side, which was managed by percutaneous drainage and laparotomy healing by secondary intention. 
Lochman and Páral: Primary Gastric Lymphoma

\section{Discussion}

Opinions regarding optimal method of primary gastric lymphoma treatment have been evolving within recent years. Thanks to improvement of diagnostic tools and method number of surgeries are continually decreasing. The next reason is relatively high postoperative morbidity and comparable results of non-surgical methods of treatment. Surgery is undoubtedly not the method of choice in the treatment of primary gastric lymphomas. It has been still reserved for complicated cases (obstruction, bleeding, perforation, etc.) and those ones where local disease persists after non-surgical treatment [3-5].

\section{Conclusion}

Even the optimal method of treatment of primary gastric lymphomas is still not finally defined the surgery may play an important role in the management of locally advanced cases or that ones with symptoms of acute abdomen as presented in our case.

\section{Statement of Ethics}

The paper complies with the guidelines for human studies in accordance with the World Medical Association Declaration of Helsinki. The patient has given the informed written consent to publish his case including images.

\section{Conflict of Interest Statement}

The authors have no conflicts of interest to declare.

\section{Funding Sources}

This work was supported by a long-term organization development plan 1011 - Clinical fields (2017-2020), Faculty of Military Health Sciences, University of Defence, Czech Republic.

\section{Author Contributions}

P.L. wrote the main text of the manuscript and provided photographs; J.P. did the final revision of the text. Both the authors approved the final version of the manuscript.

\section{References}

1 Al-Akwaa AM, Siddiqui N, Al-Mofleh IA. Primary gastric lymphoma. World J Gastroenterol. 2004;10(1):5-11.

2 Ahmad A, Govil Y, Frank BB. Gastric mucosa-associated lymphoid tissue lymphoma. Am J Gastroenterol. 2003; 98(5):975-86.

3 Aviles A, Nambo MJ, Neri N, Huerta-Guzmán J, Cuadra I, Alvarado I, et al. The role of surgery in primary gastric lymphoma. Results of a controlled clinical trial. Ann Surg. 2004;240:44-50.

4 Yoon SS, Coit DG, Portlock CS, Karpeh MS. The diminishing role of surgery in the treatment of gastric lymphoma. Ann Surg. 2004;240:28-37.

5 Cohen SM, Petryk M, Varma M, Kozuch PS, Ames ED, Grossbard ML. Non-Hodgkin's lymphoma of mucosaassociated lymphoid tissue. Oncologist. 2006 Nov-Dec;11(10):1100-17.

\section{Karger's}

